(inter alia, the six hundred or so aggiunte made in 1572 can be explained as the minimum necessary for Bodin to obtain a renewed privilège). The great merit of Miglietti's introduction lies in the close analysis she has made of the book's structure and of the text itself: a minor suppression in 1572 reveals Bodin's hardening attitude towards the Huguenots; a few words added here and there show what he has been reading or the social and intellectual contacts he has made. But she devotes the largest section of the introduction (35-44) to understanding how in the Methodus, between 1566 and 1572, Bodin developed his concept of sovereignty as "puissance absoluë et perpetuelle d'une Republique," the idea that is the cornerstone of the Six livres that appeared four years later. From all points of view Miglietti's edition of the Methodus will serve Bodin studies in very good stead.

JOHN MCCLELLAND

Victoria College

University of Toronto

\title{
Bokdam, Sylviane.
}

Métamorphoses de Morphée. Théories du rêve et songes poétiques à la Renaissance, en France.

Paris : Honoré Champion, 2012. 1185 p. IBSN 978-2-7453-2356-9 (relié) $190 €$.

Dans le français du XVI e siècle, le terme «songe » désigne toutes les formes d'activité de l'esprit qui s'exercent durant le sommeil ainsi que les images produites par cette activité. Par extension, le terme peut s'employer dans un sens métaphorique pour désigner des produits de l'esprit présentant les caractères présumés de l'image onirique. Il désigne enfin une forme littéraire qui s'est peu à peu codifiée en genre. Dans un volume dense de plus de mille pages, Sylviane Bokdam tente de comprendre pourquoi et comment une expérience humaine se constitue en forme poétique, afin de déterminer quel rapport elle entretient avec les thèmes et problématiques qui s'y inscrivent.

Une première partie présente les conceptions théologiques, métaphysiques, psychologiques et médicales qui constituent l'arrière-plan sur lequel le $\mathrm{XVI}^{e}$ siècle pense l'expérience du rêve. La philosophie, la théologie ou l'onirocritique s'interrogent sur le rapport entre les images oniriques et leur référent (concret ou idéel), sur leur signifié (vrai ou faux) et sur leur origine 
(les puissances surnaturelles, l'âme humaine, le corps et/ou le monde) ; elles questionnent le statut ontologique et aléthique de l'image, le fonctionnement de l'imagination, la valeur du signe et font du songe une médiation entre l'âme et le monde, l'âme et le corps et surtout l'âme et Dieu. Sylviane Bokdam ne surévalue pas, comme le fait parfois la critique, le rôle de la théorie ficinienne de la vacance de l'âme parmi d'autres approches philosophiques concurrentes. Elle montre que la Renaissance ne produit pas, à proprement parler, de théorie nouvelle sur le rêve, mais puise dans les commentaires des philosophes et médecins grecs et latins tout autant qu'aux Pères et à la Bible, à la kabbale et à la philosophie arabe et, ce faisant, déplace les lignes de force et modifie les éclairages. Les théories de Jean Wier sur le songe mélancolique des sorcières ne constituent pas une innovation radicale, pas plus que les explications astrologiques "naturalistes » des phénomènes prodigieux chez Pomponazzi, mais les repositionnements de la médecine qu'elles entrainent par rapport à la théologie et à la démonologie constituent bien une nouveauté. Sylviane Bokdam détermine ainsi à quels contextes philosophiques ou théologiques la poésie de la Renaissance emprunte les termes et les concepts à partir desquels elle construit son lexique de la phénoménologie onirique. Par exemple, l'idole est tantôt l'émanation active des choses au sens démocritéen, tantôt le spectre homérique; en contexte chrétien, le terme dénonce l'autonomie dangereuse de l'homme dans ses propres projections.

La seconde partie est dédiée aux poétiques du songe en tant que forme. Elle s'ouvre sur une exploration de l'héritage médiéval qui montre, par les exemples du songe-cadre du Roman de la Rose, du songe-choix de vie illustré par Guillaume de Machaut ou par les clercs écrivains, ou encore des songes « extatiques » de Christine de Pizan, qu'au Moyen Âge, l'évolution du genre accompagne celle de la littérature allégorique et l'émergence de la fonctionauteur. Sylviane Bokdam étudie ensuite le modèle pétrarquien en soulignant l'articulation du songe, de la théologie augustinienne et de la subjectivitélyrique; elle s'attache enfin aux poètes néo-latins qui exploitent une méta-poétique du songe héritée de l'Antiquité et célèbrent dans leurs songes érotiques le sublime de l'illusion. Une deuxième section est centrée sur la poésie française envisagée dans ses rapports avec la poésie italienne, de La Concorde des deux langages de Jean Lemaire de Belges aux adaptations françaises de l'Hypnerotomachia Poliphili ou du songe que l'Arioste prête à Bradamante. Une place importante est accordée aux songes qui véhiculent des paroles d'outre-tombe, dans le 
sillage des Triomphes de Pétrarque ou du songe de Scipion. Les leçons des morts sont variées : leçons chrétiennes de la défaite de Pavie chez Guillaume Crétin, projet de "rénovation spirituelle " dans la Cabale metrifiee de Jean Thénaud, ou encore chemin à suivre pour parvenir à la «béatitude éternelle " dans Le Songe de Pantagruel de François Habert. La troisième section explore la place et les formes du songe dans la poésie amoureuse en France, d'abord chez Scève, Tyard, Péletier et Louise Labé, puis dans la poésie de la Pléiade. Enfin, la dernière section étudie les liens entre poésie et histoire, illustrés dans les « songes » des Discours de Ronsard, dans les sonnets visionnaires de Du Bellay ou dans le songe heuristique que Maurice Scève prête à Adam dans le « Livre second » du Microcosme. Les deux derniers chapitres analysent plus précisément les songes de foi : du côté protestant, les deux grandes ouvres qui recourent à la forme du songe-cadre, Le Triomfe de la Foi de Du Bartas et Les Tragiques; les épopées apocalyptiques catholiques de Jacques de Billy et de Michel Quillian ; et enfin, un songe de vocation de Guy Le Fèvre de la Boderie qui mêle les vacances ficiniennes aux degrés de la hiérarchie maïmonidienne des charismes et aux « numérations » ou « émanations » de l'arbre séphirotique de la kabbale.

On ne peut que louer l'érudition de Sylviane Bokdam, la richesse et la finesse de ses analyses stimulantes. Les songes sont toujours des textes « forts ", porteurs des enjeux majeurs de la poésie du siècle : la vocation spirituelle du poète, le drame du salut, la transmission de la mémoire, le sens de l'histoire, le statut ontologique de l'image poétique, la nature de l'expérience esthétique.

VIRGINIE LEROUX

Université de Reims

Charles, Sébastien et Syliane Malinowski-Charles, éds.

Descartes et ses critiques. Actes du colloque international organisé dans le cadre du Congrès annuel de l'Association francophone pour le savoir. Québec, mai 2008.

Laval : Les Presses de l'Université Laval / Les Éditions du CIERL, 2011. 282 p. ISBN 978-2-7637-8923-1.

Pourquoi Descartes et ses critiques aujourd'hui ? C'est la question que demandent Sébastien Charles et Syliane Malinkowski-Charles dans leur introduction 